\title{
Presynaptic translation: stepping out of the postsynaptic shadow
}

\author{
Michael R. Akins ${ }^{1 \dagger}$, Hanna E. Berk-Rauch ${ }^{2 \dagger}$ and Justin R. Fallon ${ }^{*}$ \\ Department of Neuroscience, Brown University, Providence, RI, USA \\ Graduate Program in Molecular Biology, Cell Biology, and Biochemistry, Brown University, Providence, RI, USA
}

Edited by:

Hollis Cline, Cold Spring Harbor, USA

Reviewed by:

Wayne S. Sossin, McGill University,

Canada

*Correspondence:

Justin R. Fallon, Department of Neuroscience, Brown University, Box G-LN, Providence, RI 02912, USA. e-mail: justin_fallon@brown.edu

${ }^{+}$Michael R. Akins and Hanna E. Berk-Rauch have contributed equally to the work.
The ability of the nervous system to convert transient experiences into long-lasting structural changes at the synapse relies upon protein synthesis. It has become increasingly clear that a critical subset of this synthesis occurs within the synaptic compartment. While this process has been extensively characterized in the postsynaptic compartment, the contribution of local translation to presynaptic function remains largely unexplored. However, recent evidence highlights the potential importance of translation within the presynaptic compartment. Work in cultured neurons has shown that presynaptic translation occurs specifically at synapses undergoing long-term plasticity and may contribute to the maintenance of nascent synapses. Studies from our laboratory have demonstrated that Fragile X proteins, which regulate mRNA localization and translation, are expressed at the presynaptic apparatus. Further, mRNAs encoding presynaptic proteins traffic into axons. Here we discuss recent advances in the study of presynaptic translation as well as the challenges confronting the field. Understanding the regulation of presynaptic function by local protein synthesis promises to shed new light on activity-dependent modification of synaptic architecture.

Keywords: local translation, presynaptic plasticity, synaptic plasticity, fragile $X$ syndrome, FMRP, mTOR, mRNA, autism

\section{LOCAL TRANSLATION IN NEURONS}

Neurons are exquisitely polarized. This polarity places nontrivial cell biological constraints on these cells. Dendrites and axons not only have segregated functions, but they are also distinct cytoplasmic domains that typically occupy far more volume than the soma. In addition, synaptic terminals can be more than a meter removed from the nucleus. The cell-cell interactions of dendrites and axons are diverse and complex: segments of the dendritic arbor receive distinct input, while axon collaterals of a given neuron often innervate several disparate targets. Furthermore, neighboring boutons from the same axon can have distinct morphologies and release properties (Pelkey and McBain, 2008). Local metabolic, signaling and structural requirements thus vary widely in different portions of the same cell. Neurons employ multiple approaches to address this complexity. Through a combination of motor and adaptor proteins, protein cargo can be synthesized in the soma and then transported to specific subcellular locales (Goldstein et al., 2008; Hirokawa and Noda, 2008). Neuronal processes also maintain the ability to synthesize proteins in response to specific local requirements. Local protein synthesis in dendrites and the postsynaptic apparatus has been extensively investigated for almost 30 years (Steward and Levy, 1982; Sutton and Schuman, 2006; Bramham and Wells, 2007). More recently, it has become clear that local translation also occurs within axons, growth cones and presynaptic compartments. Moreover, it seems likely that translation in each of these compartments mediates distinct functions (Box 1). The focus of this review will be on recent studies pointing to local protein synthesis in the presynaptic compartment.

\section{LOCAL PRESYNAPTIC TRANSLATION}

Our understanding of presynaptic translation is informed by experiments from several systems. The earliest evidence came from studies showing the rapid incorporation of radiolabeled amino acids into presynaptic proteins in intact rat brains (Droz and Barondes, 1969) - although the precise site of synthesis was not determined in that work. More recently, experiments in cultured neurons, particularly in neurons whose axons have been severed from their soma, have provided evidence that local translation contributes to synaptic properties. Further improvements in the visualization of individual transcripts and newly translated proteins have enabled rapid advances in our understanding of how and where presynaptic translation occurs.

Presynaptic translation has been best elucidated in invertebrates. Although invertebrate neurons have morphologies that are considerably less polarized than the majority of vertebrate neurons, they have been the most tractable system for establishing a functional role for presynaptic translation in synaptic plasticity. For example, long-term facilitation (LTF) does not require the cell body of the presynaptic neuron and is blocked by local application of protein synthesis inhibitors in both cultured Aplysia neurons (Martin et al., 1997; Sherff and Carew, 1999; Liu et al., 2003) and isolated crayfish preparations (Beaumont et al., 2001). Presynaptic translation was demonstrated in the crayfish by injecting a membrane-impermeant protein synthesis inhibitor into either severed axons or into the postsynaptic muscle. Only the presynaptic injection blocked LTF induction (Beaumont et al., 2001). The Aplysia system demonstrates that the precise mechanism of LTF-induction is important. In one 

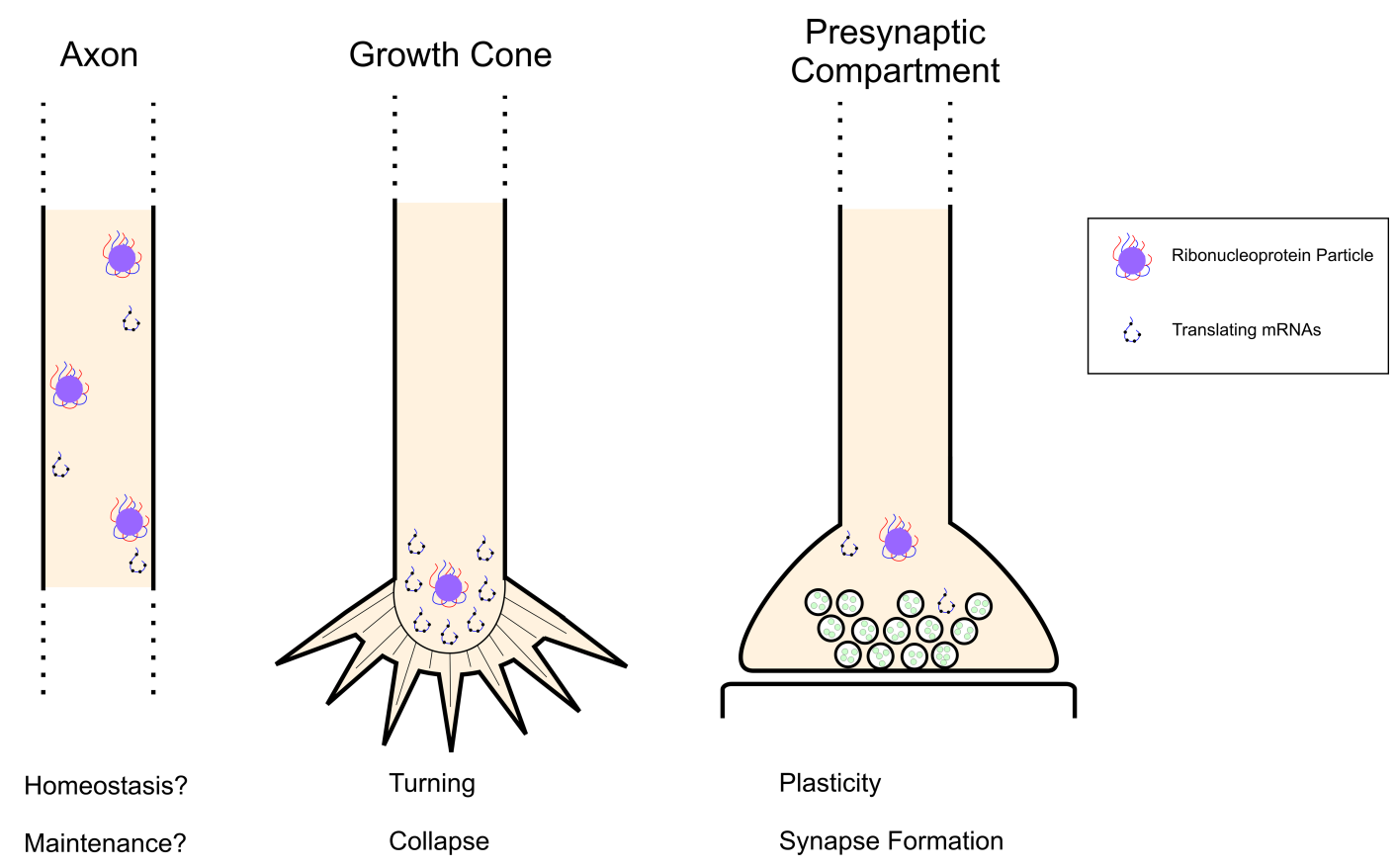

BOX 1 | Presynaptic translation is distinct from that in axons and growth cones.

Axons: Local protein synthesis has been demonstrated in axons from both invertebrates and vertebrates (reviewed in Alvarez et al., 2000; Wang et al., 2007; Lin and Holt, 2008). Messages translated include those encoding ribosomal subunits as well as heat shock, cytoskeletal and endoplasmic reticulum proteins. Gene products involved in maintaining homeostasis are also synthesized in axons. The cohort of mRNAs that localize to axons is regulated by a variety of factors including neuronal maturation, axotomy, and exposure to neurotrophins (Willis et al., 2005, 2007; Taylor et al., 2009).

Growth Cones: The importance of protein synthesis in growth cone turning and collapse has been shown in neurons cultured from invertebrates and vertebrates, including rodents (reviewed in Lin and Holt, 2007), but see (Roche et al., 2009). Growth cones synthesize cytoskeletal and signaling proteins and contain ultrastructurally identifiable polyribosomes (Bunge, 1973; Bassell et al., 1998; Campbell and Holt, 2001; Wu et al., 2005; Leung et al., 2006).

Presynaptic compartment: Local protein synthesis has been implicated in both synapse formation and plasticity. Synapse formation in Aplysia depends on local protein production. Local presynaptic translation is required for presynaptic plasticity in Aplysia, crayfish, and Xenopus and is implicated in presynaptic plasticity in rodents. See text for references. stimulus paradigm, protein synthesis was required in the presynaptic, but not postsynaptic, neuron (Martin et al., 1997), while a different induction protocol required protein synthesis in both neurons (Sherff and Carew, 1999, 2004). LTF induction is sensitive to the mTOR inhibitor rapamycin in both systems (Casadio et al., 1999; Beaumont et al., 2001). Furthermore, a requirement for calcineurin, MAP kinase and phosphatidylinositol 3-OH kinase activities was shown in the crayfish preparation (Beaumont et al., 2001).

Identification of the messages that are locally translated is key to understanding the precise function of presynaptic translation. Recent studies from invertebrates have begun to shed light on this question. The most rigorous characterization of such a target has been of the presynaptic localization and translation of the mRNA encoding the neuropeptide sensorin in Aplysia. Sensorin message rapidly localizes to synapses following contact with appropriate postsynaptic targets, and destabilizing this message, but not the existing protein, inhibits synapse formation (Schacher et al., 1999; Lyles et al., 2006). Serotonin-induced LTF increases sensorin levels in isolated neurites in a protein synthesis-dependent manner (Liu et al., 2003). Furthermore, reporters under the control of the sensorin $5^{\prime}$ and $3^{\prime}$ UTRs are translated locally at the presynaptic site in response to serotonin stimulation (Wang et al., 2009). Of particular interest, this local translation only occurs if the neurite has formed a synapse and requires calcium signaling in the postsynaptic neuron (Cai et al., 2008; Wang et al., 2009). These experiments demonstrate that mRNAs are translated at the presynaptic apparatus. Further, these studies show the importance of transsynaptic interactions in the localization and translation of presynaptic messages.

Translation at the presynaptic terminal may also regulate local protein synthesis itself. Two transcripts implicated from work in Aplysia are the elongation factor eEF1A and the translational regulator $\mathrm{CPEB}$. Serotonin induces the transport of eEF1A transcripts into neurites. Notably, knockdown of eEF1A function prevents maintenance of LTF (Giustetto et al., 2003). Furthermore, serotonin-induced presynaptic translation of $\mathrm{CPEB}$, which may lead to local accumulation of highly active CPEB, is necessary for LTF stabilization and persistence (Si et al., 2003a,b; Miniaci et al., 2008). The regulated local synthesis of translational components could prime specific presynaptic sites to respond more robustly to subsequent signals. Such a mechanism could potentially underlie aspects of memory consolidation or retrieval. 
A range of studies support a functionally relevant role for local protein synthesis in vertebrates. Local translation is required for synaptic vesicle recycling, but not postsynaptic function at a subpopulation of synapses in both immature and mature rat hippocampal cultures (Sebeo et al., 2009). Furthermore, presynaptic CaMKII $\alpha$ is required for maintenance of these synapses and is rapidly degraded when translation is suppressed. In Xenopus nervemuscle cultures, BDNF induces synaptic potentiation that can be inhibited by the injection of a membrane-impermeant translation inhibitor into the presynaptic neuron (Zhang and Poo, 2002). This protein synthesis-dependent potentiation was also observed in preparations where the axon was severed from the cell body. The specificity of this inhibition was underscored by the finding that NT3-mediated potentiation in this system was independent of protein synthesis. Presynaptic translation has also been implicated in LTD and LTP in corticostriatal and hippocampal mossy fiber synapses (Huang and Hsu, 2004; Yin et al., 2006). In both cases, translation-dependent plasticity was observed in slice cultures in which the axons had been surgically separated from their somata. Bath application of protein synthesis inhibitors perturbed plasticity, while direct injection of protein synthesis inhibitors into the postsynaptic neuron had no effect. While these slice experiments could not rule out a contribution of glial protein synthesis, they provide further support for local translation in mammalian presynaptic plasticity.

\section{PRESYNAPTIC RNA BINDING PROTEINS}

One way to understand the regulation of presynaptic translation is by assessing the localization and function of RNA binding proteins, a broad class of factors that regulate mRNA processing, subcellular distribution and regulation. Analyses in Drosophila have revealed a variety of RNA binding proteins that are critical for presynaptic formation and function. For example, transgenically-expressed Imp localizes to presynaptic sites, and synapses are smaller (but normal in number) in Imp mutants (Boylan et al., 2008). Further, flies null for $d f x r$ (a Fragile X protein homolog, see below) exhibit altered neurotransmission, abnormal presynaptic structure, increased synaptic vesicle pools, and deficits in synaptogenesis (Zhang et al., 2001; Gatto and Broadie, 2008). These animals exhibit an overexuberant axonal arbor - which could reflect abnormal activity-dependent pruning (Zhang et al., 2001; Pan et al., 2004; Tessier and Broadie, 2008). The RNA binding proteins Pumilio and Nanos, which suppress translation of target transcripts, also regulate synapse structure at the neuromuscular junction during development (Menon et al., 2004, 2009). Notably, these studies failed to detect dFXR, Pumilio or Nanos at the presynaptic site using immunohistochemistry (Zhang et al., 2001; Menon et al., 2004, 2009). It is not clear whether this finding reflects an absence of protein in the presynaptic compartment or technical challenges in visualization (see below).

Several lines of evidence support a role for Fragile $\mathrm{X}$ protein family at mammalian presynaptic specializations. This family comprises FMRP, FXR2P and FXR1P (Fragile X mental retardation protein and the two Fragile X-related proteins, respectively). An elegant demonstration of the importance of FMRP in the presynaptic cell was achieved in a system where half the neurons lack this protein due to $\mathrm{X}$-inactivation. In this preparation the likelihood of synapse formation was reduced only if the presynaptic neuron lacked FMRP (Hanson and Madison, 2007). Furthermore, mice mutated in both FMRP and FXR2P show defective baseline synaptic transmission and short-term presynaptic plasticity at 4-6 weeks (but not at 4-6 months; Zhang et al., 2009).

\section{FRAGILE X GRANULES}

Understanding the presynaptic role of the Fragile $\mathrm{X}$ proteins requires precise knowledge of their subcellular localization and circuit-level expression. Immunoelectron microscopy shows that FMRP is expressed presynaptically in a subset of neurons in the intact brain (Feng et al., 1997; Christie et al., 2009). Further, recent work from our lab has identified the Fragile X proteins as components of a novel presynaptic structure, the FXG (Fragile X granule; Christie et al., 2009). Notably, FXG expression is restricted to a subset of axons and presynaptic sites in several brain regions. Of interest, at least two of these FXG-expressing neurons exhibit long-term presynaptic plasticity (hippocampal mossy fiber and cerebellar parallel fiber terminals; Salin et al., 1996; Nicoll and Schmitz, 2005). In almost all cases, FXGs are only observed during discrete developmental epochs. Sustained FXG expression was observed only in olfactory glomeruli, a structure that continues to incorporate axons from newly born olfactory sensory neurons throughout life. FXG expression is thus linked to the periods in development and adult neurogenesis when newly generated neurons are integrating into circuits in an activity dependent manner.

\section{CHALLENGES AND FUTURE DIRECTIONS RIBOSOMES IN THE PRESYNAPTIC COMPARTMENT?}

One of the first and strongest clues for local translation in dendrites and postsynaptic spines was the detection of polyribosomes in these compartments (Steward and Levy, 1982). However, polyribosomes have not yet been detected in presynaptic compartments. The failure to detect these structures could be due to their scarcity and/or to their presence in subcellular domains that are not favorable for their ultrastructural identification (e.g., electron-dense regions; Koenig et al., 2000). Notably, axonal polyribosomes have been identified biochemically, but not ultrastructurally (Zheng et al., 2001). Biochemical purification of the presynaptic compartment has proven very difficult; therefore, high-resolution localization of protein synthetic machinery would seem to be the most promising approach. The possibility that presynaptic translation is mediated by monoribosomes should also be considered.

\section{RNA BINDING PROTEINS IN THE PRESYNAPTIC COMPARTMENT?}

Understanding the mechanisms mediating the localization and translation of presynaptic mRNAs is essential to advancing this field. To our knowledge, the only endogenous RNA-binding proteins that have been identified in presynaptic compartments are those of the Fragile X family, which reside in FXGs (Christie et al., 2009). FXGs are expressed at only a select subset of synapses in a developmentally regulated manner. Undoubtedly, other translational regulatory proteins will play a role at these and other synapses. Indeed, many RNA-binding proteins localize to and function in axons and growth cones (Aronov et al., 2002; Atlas et al., 2004; Smith et al., 2004; Hengst et al., 2006; 
van Niekerk et al., 2007; Cox et al., 2008; Miller et al., 2009). A similar diversity of RNA-binding proteins likely exists at presynaptic sites. It will be necessary to mount a concerted effort to localize these proteins at synapses. Many RNA-binding proteins are present at postsynaptic sites, and it is difficult to resolve most presynaptic specializations in intact brain by light microscopy. Therefore, it seems likely that immunoelectron microscopy or more sophisticated light microscopy will be necessary to definitively demonstrate the localization of RNA binding proteins to presynaptic compartments.

\section{PROTEIN PROCESSING MACHINERY IN THE PRESYNAPTIC COMPARTMENT?}

Many of the mRNAs that are candidates for local presynaptic translation (see Table 1 below) encode transmembrane proteins. Rough endoplasmic reticulum and Golgi apparatus have not been identified at synapses, suggesting that their roles must be filled by functional analogs. Similarly, axons do not contain ultrastructurally identifiable rough endoplasmic reticulum or Golgi. Interestingly, axons do contain protein components of these structures, including chaperones and processing enzymes necessary for the cotranslational processing of membrane proteins (Merianda et al., 2009).

\section{IDENTIFICATION OF PRESYNAPTIC RNAS}

Virtually all studies on presynaptic translation have employed general protein synthesis inhibitors or have focused on the local translation of a single transcript. However, there are likely to be many mRNAs whose presynaptic expression is locally controlled. Table 1 presents a list of candidate mRNAs that may be locally translated at the presynaptic apparatus. This set comprises transcripts that are present in axons and/or are associated with FMRP (see Table $\mathbf{1}$ for references). Strikingly, almost the entire synaptic vesicle cycle is represented in this compilation. Regulated local translation of such a variety of components would allow for a remarkable degree of local control of synapse stability and vesicle release properties. We stress that the messages in Table 1 are candidates. Localizing these RNAs to the presynaptic compartment and demonstrating their role in synaptic function or plasticity will be of great interest. Targeted screens to identify additional candidates are also needed. One attractive approach would be to identify RNAs associated with tagged proteins expressed specifically in presynaptic neurons, such as GFP-tagged ribosomal proteins (Doyle et al., 2008).

\section{DOES PRESYNAPTIC TRANSLATION PERSIST THROUGHOUT LIFE?}

Synapse formation and plasticity are most robust during early postnatal periods. However, axonal arbors maintain significant plasticity even in the adult nervous system (Gogolla et al., 2007). For example, long-term in vivo imaging has revealed a subpopulation of relatively labile presynaptic boutons in the adult brain (De Paola et al., 2006; Stettler et al., 2006). It is possible that such labile synapses may depend upon local translation in a manner similar to the small synapses observed in mature hippocampal cultures (Sebeo et al., 2009). Furthermore, recent work from C. elegans suggests that local presynaptic translation takes place in the mature nervous system, and that regulating or suppressing this capacity is required for maintenance of synapse and axon morphology (Yan et al., 2009). Thus, presynaptic translation could also play a role in the adult brain.

Table 1 | Candidate mRNAs for local presynaptic translation. The list comprises transcripts encoding proteins with a presynaptic function that meet one or more of the following criteria: Localization to axons (Taylor et al., 2005, 2009; Bi et al., 2006), binding to FMRP (Darnell et al., 2001; Miyashiro et al., 2003), or FMRP-dependent ribosome association (Brown et al., 2001). Standard names are given for messages originally identified by their Kazuso (KIAA) cDNA sequencing project numbers.

\begin{tabular}{ll}
\hline & References \\
\hline RECEPTORS & \\
א-opioid receptor & Bi et al. (2006) \\
GRINL1a, NMDA & Taylor et al. (2009) \\
$\quad$ Receptor-Like 1A & \\
GABRG3, GABA-A Receptor $\gamma$-3 & Taylor et al. (2009) \\
GABRE, GABA-A Receptor $\varepsilon$ & Taylor et al. (2009) \\
Cannabinoid Receptor 1 & Miyashiro et al. (2003) \\
5-HT Receptor 2 & Miyashiro et al. (2003)
\end{tabular}

\section{ACTIVE ZONE PROTEINS}

RIM1

Liprin $\alpha 3$

Munc13

CASK

RIM-Binding Protein 2

VESICLE PROTEINS

\section{Rab3a}

Synaptotagmin 5

Synaptotagmin 11

SNAPAP/Snapin

Synaptophysin

Synapsin

\section{SNAREs}

Syntaxin 3

Syntaxin 5A

Syntaxin 7

SNAP23

SNAP25

SNAP29

VAMP1/Synaptobrevin 1

VAMP2/Synaptobrevin 2

VAMP3/Synaptobrevin 3

VESICLE RECYCLING

Clathrin, heavy polypeptide

Clathrin, light polypeptide

Dynamin 1

Arp2

Arp3

Synaptojanin 2

\section{OTHER}

Neurexin 3

TARP $\gamma$-8/CACNG8

$\beta$-Catenin

Neuroligin 2

Synaptotagmin-Like 4

$\alpha$-Synuclein

BASP1/NAP-22

SEC6-Like 1
Miyashiro et al. (2003)

Taylor et al. (2009)

Taylor et al. (2009)

Darnell et al. (2001)

Miyashiro et al. (2003)

Brown et al. (2001)

Miyashiro et al. (2003)

Miyashiro et al. (2003)

Miyashiro et al. (2003)

Brown et al. (2001)

Taylor et al. (2005, 2009)

Taylor et al. (2009)

Miyashiro et al. (2003)

Miyashiro et al. (2003), Taylor et al. (2009)

Miyashiro et al. (2003), Taylor et al. (2009)

Brown et al. (2001)

Miyashiro et al. (2003), Taylor et al. (2009)

Taylor et al. (2009)

Taylor et al. (2009)

Miyashiro et al. (2003)

Miyashiro et al. (2003)

Taylor et al. (2009)

Miyashiro et al. (2003)

Miyashiro et al. (2003)

Miyashiro et al. (2003)

Miyashiro et al. (2003)

Miyashiro et al. (2003)

Taylor et al. (2009)

Taylor et al. (2009)

Taylor et al. (2009)

Taylor et al. (2009)

Taylor et al. (2009)

Taylor et al. (2009)

Brown et al. (2001), Darnell et al. (2001),

Taylor et al. (2009)

Taylor et al. (2009) 


\section{PRESYNAPTIC PROTEIN SYNTHESIS IN CONTEXT}

Local presynaptic protein synthesis is likely to coordinate with translation in the postsynaptic and somatic compartments to regulate changes in synapse morphology. For example, while presynaptic protein synthesis is required for LTF in Aplysia, the pattern of serotonin application determines the relative contributions of pre- and post-synaptic translation (Sherff and Carew, 2004). Even in a system where postsynaptic protein synthesis is not required for LTF, serotonin application results in the new synthesis of postsynaptic receptors (Trudeau and Castellucci, 1995). Furthermore, most forms of LTF result in a protein synthesis-dependent local increase in the complexity of the axonal arbor (Glanzman et al., 1990; Bailey et al., 1992; Casadio et al., 1999; Hatada et al., 2000). While local translation is required for the initiation of this outgrowth, sustained growth and maintenance of the elaborated arbor requires somatic protein synthesis (Grabham et al., 2005). Taken together, these data suggest a model in which local protein synthesis in both synaptic compartments tags a particular subset of synapses for remodeling. Locally synthesized proteins are sufficient to begin this process, but proteins synthesized within the soma are required to maintain the new synaptic architecture.

\section{FUTURE DIRECTIONS}

Could presynaptic translation play a role in brain disorders? Interestingly, defects in local synaptic translation may be a common feature of several single-gene disorders with a high prevalence of autism (Kelleher and Bear, 2008). Fragile X syndrome arises from mutations in FMRP, while tuberous sclerosis and PTEN hamartoma syndrome

\section{REFERENCES}

Alvarez, J., Giuditta, A., and Koenig, E. (2000). Protein synthesis in axons and terminals: significance for maintenance, plasticity and regulation of phenotype: with a critique of slow transport theory. Prog. Neurobiol. 62, $1-62$.

Aronov, S., Aranda, G., Behar, L., and Ginzburg, I. (2002). Visualization of translated tau protein in the axons of neuronal P19 cells and characterization of tau RNP granules. J. Cell. Sci. 115, 3817-3827.

Atlas, R., Behar, L., Elliott, E., and Ginzburg, I. (2004). The insulin-like growth factor mRNA binding-protein IMP- 1 and the Ras-regulatory protein G3BP associate with tau mRNA and $\mathrm{HuD}$ protein in differentiated P19 neuronal cells. J. Neurochem. 89, 613-626.

Bailey, C. H., Montarolo, P., Chen, M., Kandel, E. R., and Schacher, S. (1992). Inhibitors of protein and RNA synthesis block structural changes that accompany long-term heterosynaptic plasticity in Aplysia. Neuron 9, 749-758.

Bassell, G. J.,Zhang, H., Byrd,A. L., Femino, A. M., Singer, R. H., Taneja, K. L., Lifshitz, L. M., Herman, I. M., and Kosik, K. S. (1998). Sorting of betaactin mRNA and protein to neurites

patients show defective mTOR signaling. Notably, both FMRP and mTOR are implicated in presynaptic translation. Additionally, mutations in neurexins and neuroligins (which are candidates for local presynaptic translation-Table 1) underlie multiple neurological disorders including familial autism (reviewed in Sudhof, 2008). It is an intriguing possibility that the cognitive and behavioral deficits apparent in autistic patients could arise in part from alterations of local translation in the presynaptic compartment. Perturbations in this process could result in abnormal experience-dependent synaptic plasticity - a leading hypothesis for the neurobiological cause of autism.

The field of presynaptic translation is entering an exciting period. Mounting evidence demonstrates that this phenomenon occurs in at least a subset of neurons. Technical advances for detecting mRNAs and newly synthesized proteins are opening the way to more comprehensive and definitive studies. At the same time, major questions about the expression and regulation of presynaptic translation will need to be addressed. Chief among these is the systematic identification of the synaptic populations at which presynaptic translation occurs and the factors that initiate and terminate local translation. Elucidating these questions will lead to a deeper understanding of the diverse pathways by which neuronal circuits are organized and maintained and could point to new therapeutic targets for autism, Fragile X syndrome and other synaptic diseases.

\section{ACKNOWLEDGMENTS}

We thank members of the Fallon lab for critical review of this manuscript. Work in our lab is funded by DA021501 (Michael R. Akins) and HD052083 (Justin R. Fallon).

brain mRNAs and altered mRNA translational profiles in Fragile X syndrome. Cell 107, 477-487.

Bunge, M. B. (1973). Fine structure of nerve fibers and growth cones of isolated sympathetic neurons in culture. J. Cell Biol. 56, 713-735.

Cai, D., Chen, S., and Glanzman, D. L. (2008). Postsynaptic Regulation of long-term facilitation in Aplysia. Curr. Biol. 18, 920-925.

Campbell, D. S., and Holt, C. E. (2001). Chemotropic responses of retinal growth cones mediated by rapid local protein synthesis and degradation. Neuron 32, 1013-1026.

Casadio, A., Martin, K. C., Giustetto, M. Zhu, H., Chen, M., Bartsch, D., Bailey, C.H., and Kandel, E. R. (1999). A transient, neuron-wide form of CREB-mediated long-term facilitation can be stabilized at specific synapses by local protein synthesis. Cell 99 , 221-237.

Christie, S. B., Akins, M. R., Schwob, J. E., and Fallon, J.R. (2009). The FXG: a presynaptic Fragile X granule expressed in a subset of developing brain circuits. J. Neurosci. 29, 1514-1524.

Cox, L. J., Hengst, U., Gurskaya, N. G., Lukyanov, K. A., and Jaffrey, S. R. (2008). Intra-axonal translation and retrograde trafficking of CREB promotes neuronal survival. Nat. Cell Biol. 10, 149-159.

Darnell, J. C., Jensen, K. B., Jin, P., Brown, V., Warren, S. T., and Darnell, R. B. (2001). Fragile X mental retardation protein targets $\mathrm{G}$ quartet mRNAs important for neuronal function. Cell 107, 489-499.

De Paola, V., Holtmaat, A., Knott, G., Song, S., Wilbrecht, L., Caroni, P., and Svoboda, K. (2006). Cell type-specific structural plasticity of axonal branches and boutons in the adult neocortex. Neuron 49, 861-875.

Doyle, J. P., Dougherty, J. D., Heiman, M., Schmidt, E. F., Stevens, T. R., Ma, G., Bupp, S., Shrestha, P., Shah, R. D. Doughty,M.L., Gong, S., Greengard, P., and Heintz, N. (2008). Application of a translational profiling approach for the comparative analysis of CNS cell types. Cell 135, 749-762.

Droz, B., and Barondes, S. M. (1969). Nerve endings: rapid appearance of labeled protein shown by electron microscope radioautography. Science 165, 1131-1133.

Feng, Y., Gutekunst, C., Eberhart, D. E., Yi, H., Warren, S. T., and Hersch, S. M. (1997). Fragile X mental retardation protein: nucleocytoplasmic shuttling and association with somatodendritic ribosomes. J. Neurosci. 17, 1539-1547. 
Gatto, C. L., and Broadie, K. (2008). Temporal requirements of the fragile X mental retardation protein in the regulation of synaptic structure. Development 135, 2637-2648.

Giustetto, M., Hegde, A. N., Si, K., Casadio, A., Inokuchi, K., Pei, W., Kandel, E. R., and Schwartz, J. H. (2003). Axonal transport of eukaryotic translation elongation factor $1 \alpha$ mRNA couples transcription in the nucleus to long-term facilitation at the synapse. Proc. Natl. Acad. Sci. U.S.A. 100, 13680-13685.

Glanzman, D. L., Kandel, E. R., and Schacher, S. (1990). Target-dependent structural changes accompanyinglongterm synaptic facilitation in Aplysia neurons. Science 249, 799-802.

Gogolla, N., Galimberti, I., and Caroni, P. (2007). Structural plasticity of axon terminals in the adult. Curr. Opin. Neurobiol. 17, 516-524.

Goldstein, A. Y., Wang, X., and Schwarz, T. L. (2008). Axonal transport and the delivery of pre-synaptic components. Curr. Opin. Neurobiol. 18, 495-503.

Grabham, P. W., Wu, F., Schacher, S., and Goldberg, D. J. (2005). Initiating morphological changes associated with long-term facilitation in Aplysia is independent of transcription or translation in the cell body. J. Neurobiol. 64, 202-212.

Hanson, J. E., and Madison, D. V. (2007). Presynaptic Fmrl genotype influences the degree of synaptic connectivity in a mosaic mouse model of Fragile X syndrome. J. Neurosci. 27, 4014-4018.

Hatada, Y., Wu, F., Sun, Z., Schacher, S., and Goldberg, D. J. (2000). Presynaptic morphological changes associated with long-term synaptic facilitation are triggered by actin polymerization at preexisting varicositis. J. Neurosci. 20, 82RC.

Hengst, U., Cox, L. J., Macosko, E. Z., and Jaffrey, S. R. (2006). Functional and selective RNA interference in developing axons and growth cones. J. Neurosci. 26, 5727-5732.

Hirokawa, N., and Noda, Y. (2008). Intracellular transport and kinesin superfamily proteins, KIFs: structure, function, and dynamics. Physiol. Rev. 88, 1089-1118.

Huang, C., and Hsu, K. (2004). Local protein synthesis and $\mathrm{GABAB}$ receptors regulate the reversibility of long-term potentiation at murine hippocampal mossy fibre-CA3 synapses. J. Physiol. 561, 91-108.

Kelleher, R. J., and Bear, M. F. (2008). The autistic neuron: troubled translation? Cell 135, 401-406.

Koenig, E., Martin, R., Titmus, M., and Sotelo-Silveira, J. R. (2000). Cryptic peripheral ribosomal domains distributed intermittently along mammalian myelinated axons. J. Neurosci. 20, 8390-8400.

Leung, K., van Horck, F. P., Lin, A. C., Allison, R., Standart, N., and Holt, C. E. (2006). Asymmetrical beta-actin mRNA translation in growth cones mediates attractive turning to netrin1. Nat. Neurosci. 9, 1247-1256.

Lin, A. C., and Holt, C. E. (2007). Local translation and directional steering in axons. EMBO J. 26, 3729-3736.

Lin, A. C., and Holt, C. E. (2008). Function and regulation of local axonal translation. Curr. Opin. Neurobiol. 18, 60-68.

Liu, K., Hu, J.-Y., Wang, D., and Schacher, S. (2003). Protein synthesis at synapse versus cell body: enhanced but transient expression of long-term facilitation at isolated synapses. J. Neurobiol. 56, 275-286.

Lyles, V., Zhao, Y., and Martin, K. C. (2006). Synapse formation and mRNA localization in cultured aplysia neurons. Neuron 49, 349-356.

Martin, K. C., Casadio, A., Zhu, H., Yaping, E., Rose, J. C., Chen, M., Bailey, C. H., and Kandel, E. R. (1997). Synapse-specific, long-term facilitation of aplysia sensory to motor synapses: a function for local protein synthesis in memory storage. Cell 91, 927-938.

Menon, K. P., Andrews, S., Murthy, M., Gavis, E. R., and Zinn, K. (2009). The translational repressors nanos and pumilio have divergent effects on presynaptic terminal growth and postsynaptic glutamate receptor subunit composition. J. Neurosci. 29, 5558-5572.

Menon, K.P., Sanyal, S.,Habara, Y.,Sanchez, R., Wharton, R. P., Ramaswami, M., and Zinn, K. (2004). The translational repressor pumilio regulates presynaptic morphology and controls postsynaptic accumulation of translation factor eIF4E. Neuron 44, 663-676.

Merianda, T. T., Lin, A. C., Lam, J. S., Vuppalanchi, D., Willis, D. E., Karin, N., Holt, C. E., and Twiss, J. L. (2009). A functional equivalent of endoplasmic reticulum and Golgi in axons for secretion of locally synthesized proteins. Mol. Cell. Neurosci. 40, 128-142.

Miller, L. C., Blandford, V., McAdam, R., Sanchez-Carbente, M. R., Badeaux, F., DesGroseillers, L., and Sossin, W. S. (2009). Combinations of DEAD box proteins distinguish distinct types of RNA: protein complexes in neurons. Mol. Cell. Neurosci. 40, 485-495.

Miniaci, M. C., Kim, J., Puthanveettil, S. V., Si, K., Zhu, H., Kandel, E. R., and Bailey, C. H. (2008). Sustained CPEBdependent local protein synthesis is required to stabilize synaptic growth for persistence of long-term facilitation in Aplysia. Neuron 59, 1024-1036.

Miyashiro, K. Y., Beckel-Mitchener, A., Purk, T. P., Becker, K. G., Barret, T., Liu, L., Carbonetto, S., Weiler, I. J., Greenough, W. T., and Eberwine, J. (2003). RNA cargoes associating with FMRP reveal deficits in cellular functioning in Fmrl null mice. Neuron 37, 417-431.

Nicoll, R. A., and Schmitz, D. (2005). Synaptic plasticity at hippocampal mossy fibre synapses. Nat. Rev. Neurosci. 6, 863-876.

Pan, L., Zhang, Y. Q., Woodruff, E., and Broadie, K. (2004). The Drosophila Fragile $\mathrm{X}$ gene negatively regulates neuronal elaboration and synaptic differentiation. Curr. Biol. 14 1863-1870.

Pelkey, K. A., and McBain, C. J. (2008) Target-cell-dependent plasticity within the mossy fibre-CA3 circuit reveals compartmentalized regulation of presynaptic function at divergent release sites. J. Physiol. (Lond.) 586, 1495-1502.

Roche, F. K., Marsick, B. M., and Letourneau, P. C. (2009). Protein synthesis in distal axons is not required for growth cone responses to guidance cues. J. Neurosci. 29, 638-652.

Salin, P.A., Malenka, R. C., and Nicoll, R. A. (1996). Cyclic AMP mediates a presynaptic form of LTP at cerebellar paralle fiber synapses. Neuron 16, 797-803.

Schacher, S., Wu, F., Panyko, J. D., Sun, Z. and Wang, D. (1999). Expression and branch-specific export of mRNA are regulated by synapse formation and interaction with specific postsynaptic targets. J. Neurosci. 19, 6338-6347.

Sebeo, J., Hsiao, K., Bozdagi, O. Dumitriu, D., Ge, Y., Zhou, Q., and Benson, D. L. (2009). Requirement for protein synthesis at developing synapses. J. Neurosci. 29, 9778-9793.

Sherff, C. M., and Carew, T. J. (1999) Coincident induction of long-term facilitation in aplysia: cooperativity between cell bodies and remote synapses. Science 285, 1911-1914.

Sherff, C. M., and Carew, T. J. (2004) Parallel somatic and synaptic processing in the induction of intermediate-term and long-term synaptic facilitation in Aplysia. Proc. Natl. Acad. Sci. U.S.A. 101, 7463-7468.

Si, K., Giustetto, M., Etkin, A., Hsu, R., Janisiewicz, A. M., Miniaci, M. C., Kim, J., Zhu, H., and Kandel, E. R. (2003a). A neuronal isoform of CPEB regulates local protein synthesis and stabilizes synapse-specific longterm facilitation in Aplysia. Cell 115, 893-904.
Si, K., Lindquist, S., and Kandel, E. R. (2003b). A neuronal isoform of the aplysia CPEB has prion-like properties. Cell 115, 879-891.

Smith, C. L., Afroz, R., Bassell, G. J., Furneaux, H. M., Perrone-Bizzozero, N. I., and Burry, R. W. (2004). GAP-43 mRNA in growth cones is associated with $\mathrm{HuD}$ and ribosomes. J. Neurobiol. 61, 222-235.

Stettler, D. D., Yamahachi, H., Li, W., Denk, W., and Gilbert, C. D. (2006). Axons and synaptic boutons are highly dynamic in adult visual cortex. Neuron 49, 877-887.

Steward, O., and Levy, W. B. (1982). Preferential localization of polyribosomes under the base of dendritic spines in granule cells of the dentate gyrus. J. Neurosci. 2, 284-291.

Sudhof, T. C. (2008). Neuroligins and neurexins link synaptic function to cognitive disease. Nature 455 , 903-911.

Sutton, M.A., and Schuman, E. M. (2006). Dendritic protein synthesis, synaptic plasticity, and memory. Cell 127, 49-58.

Taylor, A. M., Berchtold, N. C., Perreau, V. M., Tu, C. H., Li Jeon, N., and Cotman, C. W. (2009). Axonal mRNA in uninjured and regenerating cortical mammalian axons. J. Neurosci. 29 , 4697-4707.

Taylor, A. M., Blurton-Jones, M., Rhee, S. W., Cribbs, D. H., Cotman, C. W. and Jeon, N. L. (2005). A microfluidic culture platform for CNS axonal injury, regeneration and transport. Nat. Methods 2, 599-605.

Tessier, C. R., and Broadie, K. (2008). Drosophila fragileXmental retardation protein developmentally regulates activity-dependent axon pruning. Development 135, 1547-1557.

Trudeau, L. E., and Castellucci, V. F. (1995). Postsynaptic modifications in long-term facilitation in Aplysia: upregulation of excitatory amino acid receptors. J. Neurosci. 15, 1275-1284.

van Niekerk,E.A., Willis, D.E., Chang, J. H., Reumann, K., Heise, T., and Twiss, J. L. (2007). Sumoylation in axons triggers retrograde transport of the RNAbinding protein La. Proc. Natl. Acad. Sci. U.S.A 104, 12913-12918.

Wang, D. O., Kim, S. M., Zhao, Y. Hwang, H., Miura, S. K., Sossin, W. S., and Martin, K.C. (2009). Synapse- and stimulus-specific local translation during long-term neuronal plasticity. Science 324, 1536-1540.

Wang, W., Niekerk, E. V., Willis, D. E., and Twiss, J. L. (2007). RNA transport and localized protein synthesis in neurological disorders and neural repair. Dev. Neurobiol. 67, 1166-1182. 
Willis, D., Li, K. W., Zheng, J., Chang, J. H., Smit, A., Kelly, T., Merianda, T. T., Sylvester, J., van Minnen, J., and Twiss, J. L. (2005). Differential transport and local translation of cytoskeletal, injury-response, and neurodegeneration protein mRNAs in axons. J. Neurosci. 25, 778-791.

Willis, D. E., van Niekerk, E. A., Sasaki, Y., Mesngon, M., Merianda, T. T., Williams, G. G., Kendall, M., Smith, D. S., Bassell, G. J., and Twiss, J. L. (2007). Extracellular stimuli specifically regulate localized levels of individual neuronal mRNAs. J. Cell Biol. 178, 965-980.

Wu, K. Y., Hengst, U., Cox, L. J., Macosko, E. Z., Jeromin, A., Urquhart, E. R., and Jaffrey, S. R. (2005). Local translation of RhoA regulates growth cone collapse. Nature 436, 1020-1024.

Yan, D., Wu, Z., Chisholm, A. D., and Jin, Y.(2009). The DLK-1 kinase promotes mRNA stability and local translation in C. elegans synapses and axon regeneration. Cell 138, 1005-1018.

Yin, H. H., Davis, M. I., Ronesi, J. A., and Lovinger, D. M. (2006). The role of protein synthesis in striatal long-term depression. J. Neurosci. 26, 11811-11820.

Zhang, J., Hou, L., Klann, E., and Nelson, D. L. (2009). Altered hippocampal synaptic plasticity in the Fmrl gene family knockout mouse models. J. Neurophysiol. 101, 2572-2580.

Zhang, X., and Poo, M. (2002). Localized synaptic potentiation byBDNFrequires local protein synthesis in the developing axon. Neuron 36, 675-688.

Zhang, Y. Q., Bailey, A. M., Matthies, H. J. G., Renden, R. B., Smith, M.A., Speese, S. D., Rubin, G. M., and Broadie, K. (2001). Drosophila Fragile X-related gene regulates the MAP1B homolog futsch to control synaptic structure and function. Cell 107, 591-603.

Zheng, J., Kelly, T. K., Chang, B., Ryazantsev, S., Rajasekaran, A. K., Martin, K. C., and Twiss, J. L. (2001). A functional role for intra-axonal protein synthesis during axonal regeneration from adult sensory neurons. J. Neurosci. 21, 9291-9303.

Conflict of Interest Statement: The authors declare that the research was conducted in the absence of any commercial or financial relationships that could be construed as a potential conflict of interest.

Received: 14 July 2009; paper pending published: 14 August 2009; accepted:07 October 2009; published online: 04 November 2009.

Citation: Akins MR, Berk-Rauch HE and Fallon JR (2009) Presynaptic translation: stepping out of the postsynaptic shadow. Front. Neural Circuits 3:17. doi: 10.3389/neuro.04.017.2009

Copyright (C) 2009 Akins, Berk-Rauch and Fallon. This is an open-access article subject to an exclusive license agreement between the authors and the Frontiers Research Foundation, which permits unrestricted use, distribution, and reproduction in any medium, provided the original authors and source are credited. 